\title{
Alterations in lipid profile in gestational diabetes mellitus (GDM) and type 2 DM women during pregnancy
}

\author{
Vani $K^{1}$ \\ ${ }^{1}$ Dr. K.Vani, Assistant Professor of Biochemistry, Sri Muthukumaran Medical College Hospital and Research Institute, \\ Chikkarayapuram, Near Mangadu, Chennai -600069.
}

Address for Correspondence: Dr K Vani, Email:Vanisankar2000@yahoo.com

\begin{abstract}
Objective: To study the effect of gestational diabetes mellitus (GDM) and type 2 diabetes mellitus (DM)on indices of lipid profile in maternal blood samples and compare them with normal pregnancies. Methodology: Blood samples were collected from 45 normal pregnant women and 30 women with GDM and 15 women with type 2 DM during pregnancy.Serum lipids which includeTotal Cholesterol, Triglycerides, Very Low Density Lipoprotein,Low Density Lipoproteinand High Density Lipoprotein were estimated using semi-automated clinical chemistry analyzer.Results:The results of the lipid profile showed elevatedlevels of Total Cholesterol, Triglycerides, Very Low Density Lipoprotein and Low Density Lipoprotein in women with GDM andpregnant type 2 DM women compared to controls. On the other hand,the High Density Lipoproteinlevels were significantly elevated in controls.Conclusion: In Gestational Diabetes Mellitus and type $2 \mathrm{DM}$ during pregnancy, the lipid profile alters in such manner that could be atherogenic and possibly harmful to the fetus.
\end{abstract}

Keywords: Gestational Diabetes Mellitus, Total Cholesterol (TC), Triglycerides (TGL),VLDL (Very Low Density Lipoprotein), LDL (Low Density Lipoprotein), HDL (High Density Lipoprotein)

\section{Introduction}

Diabetes or impaired glucose tolerance develops in 2-3 percent pregnant women, previously non-diabetic, most often in the last trimester of pregnancy. This condition is referred to as Gestational Diabetes Mellitus (GDM). It is defined as any degree of glucose intolerance with onset or first recognition during pregnancy. GDM represents nearly 90percent of all pregnancies complicated by diabetes. The insulin resistance of normal pregnancy may also contribute to GDM in women in whom the capacity for insulin secretion is not sufficient to meet the increased insulin demands of pregnancy[1].

Diabetes during pregnancy is associated with increase in maternal and perinatal morbidity. The hallmark of this condition is increased insulin resistance. Maternal hormones are thought to interfere with the action of insulin as it binds to the insulin receptor. Since insulin

Manuscript received: $24^{\text {th }}$ July 2015

Reviewed: $7^{\text {th }}$ Aug 2015

Author Corrected: $17^{\text {th }}$ Aug 2015

Accepted for Publication: $27^{\mathrm{th}}$ Aug 2015 promotes the entry of glucose into most cells, insulin resistance prevents glucose from entering the cells. As a result, glucose remains in the bloodstream, where glucose levels rise. More insulin is needed to overcome this resistance; more insulin is produced than in a normal pregnancy.

Macrosomia[2], congenital cardiac and central nervous system anomalies, skeletal malformations and respiratory distress syndrome are some of the wellknown complications occurring in infants of diabetic mothers. Moreover, human epidemiological and animal studies suggest that the intrauterine diabetic environment increases the risk of hypertension, obesity, and type II diabetes in adulthood in the offspring of diabetic mothers. Fetal hyperinsulinemia at birth acts as a marker of this risk and it may also have potential prognostic implications. Thus, higher insulin levels in utero might be a cause of later metabolic complications [3] [4] [5]. 
Normal pregnancy induces major alterations in carbohydrate; lipid and amino acidmetabolisms [6].Our study aimed to determine the changes in serum lipids during last trimester of gestational diabetes and type 2 DM during pregnancy and compare these with serum lipid levels in normal pregnancies. Lipid abnormalities include so called diabetic dyslipidemia, characterized by an elevation in triglycerides (TGL) and a moderate elevation or normal levels of LDL-cholesterol and total cholesterol concentrations in blood [7]. Plasma

\section{Materials and methods}

\section{Study Population:}

\section{a. Cases :}

The study sample comprised 30 women with GDM and 15 women with type $2 \mathrm{DM}$ during pregnancy during the third trimester.GDM women were diagnosed with oral glucose tolerance test (ADA Criteria)[10]. Both GDM and Type 2 DM women were on treatment with diet modifications, exercise and insulin.

b. Controls :

Comprised 45 normal pregnant womenattending the antenatal clinic

\section{Inclusion Criteria}

Women aged between 25-35 years and without any other medical complications of pregnancy

\section{Exclusion Criteria}

Mothers with complications like preeclampsia, preterm deliveries, twin pregnancies and those on medications which alter lipid metabolism e.g., cholesterol lowering drugs were not included in the study.

\section{Results}

Table 1: Distribution of subjects according to diabetic status

\begin{tabular}{|l|l|l|}
\hline Group & Number of Subjects & Diabetic Status \\
\hline $\mathbf{1}$ & 45 & Non-Diabetic pregnant women \\
\hline $\mathbf{2}$ & 30 & GDM women \\
\hline $\mathbf{3}$ & 15 & Pregnant type 2 DM women \\
\hline
\end{tabular}

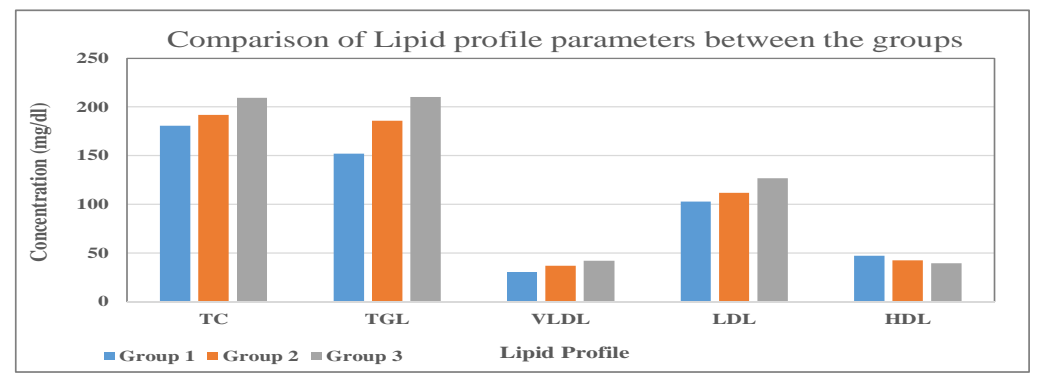

concentration of TGL, cholesterol, phospholipids and free fatty acids increase during pregnancy. The most dramatic change is the rise in fasting TGL concentration [8], which increases approximately four folds during pregnancy probably due to increased hepatic synthesis and reduced removals, induced by placental hormones [9]. Maternal lipoprotein lipase activity also favours hypertriglyceridemia.The increased specific activity of hepatic lipase induced by progesterone in turn likely affectsthe concentration of HDL-cholesterol.

\section{Sample Collection and Processing}

Patients' overnight fasting blood samples were drawn into vacutainer tube. The samples were made to stand for 1 hour for sera to separate. The samples were then centrifuged at $3000 \mathrm{rpm}$ for 5 minutes. Sera were aliquoted and stored at

$-21^{\circ} \mathrm{C}$ until ready to use.

\section{Analysis of samples}

Samples were brought to room temperature and allowed to thaw before analysis. Total cholesterol andtriglycerides were estimated by enzymatic methods[11], [12]. HDL-Cholesterol (HDL-C) was estimated byphosphotungstic acid precipitation followed byenzymatic analysis in supernatant fraction[13] andLDL-Cholesterol (LDL-C) was determined by usingFriedewald's equation[14]according to which LDL cholesterol = Total cholesterol - (HDL cholesterol+ VLDL cholesterol). VLDL cholesterol (VLDL-C) was calculated as $1 / 5$ of Triglycerides.

\section{Sample collection}


Table 2:Comparison of lipid profile parameters between thegroups

\begin{tabular}{|c|c|c|c|c|c|}
\hline Lipid profile & Groups & Mean & $\begin{array}{l}\text { Standard } \\
\text { deviation }\end{array}$ & ANOVA F & $\begin{array}{l}\text { Significance } \\
\text { (P value) }\end{array}$ \\
\hline \multirow{3}{*}{$\begin{array}{l}\text { Total cholesterol } \\
\text { (TC) }\end{array}$} & 1 & 180.7 & 10.8 & \multirow[t]{3}{*}{30.7} & \multirow[t]{3}{*}{$<0.05^{*}$} \\
\hline & 2 & 191.8 & 14.6 & & \\
\hline & 3 & 209.2 & 12.3 & & \\
\hline \multirow{3}{*}{$\begin{array}{l}\text { Triglycerides } \\
\text { (TGL) }\end{array}$} & 1 & 151.9 & 10.5 & \multirow[t]{3}{*}{116.1} & \multirow{3}{*}{$<0.05^{*}$} \\
\hline & 2 & 185.7 & 17 & & \\
\hline & 3 & 210.4 & 16.6 & & \\
\hline \multirow{3}{*}{$\begin{array}{l}\text { Very Low Density } \\
\text { Lipoprotein } \\
\text { (VLDL) }\end{array}$} & 1 & 30.3 & 2.1 & \multirow[t]{3}{*}{114.3} & \multirow{3}{*}{$<0.05^{*}$} \\
\hline & 2 & 37.1 & 3.5 & & \\
\hline & 3 & 42.2 & 3.5 & & \\
\hline \multirow{3}{*}{$\begin{array}{l}\text { Low Density } \\
\text { Lipoprotein } \\
\text { (LDL) }\end{array}$} & 1 & 102.8 & 8 & \multirow[t]{3}{*}{31} & \multirow{3}{*}{$<0.05^{*}$} \\
\hline & 2 & 112.0 & 12.8 & & \\
\hline & 3 & 126.5 & 10.8 & & \\
\hline \multirow{3}{*}{$\begin{array}{l}\text { High Density } \\
\text { Lipoprotein } \\
\text { (HDL) }\end{array}$} & 1 & 47.1 & 3.7 & \multirow[t]{3}{*}{19.1} & \multirow{3}{*}{$<0.05^{*}$} \\
\hline & 2 & 42.7 & 5.9 & & \\
\hline & 3 & 39.6 & 2.5 & & \\
\hline
\end{tabular}

\section{* - Significance}

The mean Total cholesterol levels were found to be significantly higher in women with GDM (191.8 $\pm 14.6 \mathrm{mg} / \mathrm{dl})$ and

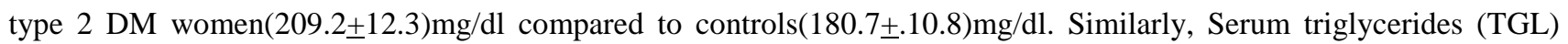
were significantly higher in women with GDM $(185.7 \pm 17) \mathrm{mg} / \mathrm{dland}$ type 2 DM women $(210.4 \pm 16.6) \mathrm{mg} / \mathrm{dl}$ as compared with controls $(151.9 \pm 10.5) \mathrm{mg} / \mathrm{dl}$. Such a significance was also seen in the case of VLDL and LDL, with the mean VLDL being(37.1 \pm 3.5$) \mathrm{mg} / \mathrm{dl}$ in GDM,(42.2 \pm 3.5$) \mathrm{mg} / \mathrm{dl}$ in type $2 \mathrm{DM}$ and the mean LDL being $(112 \pm 12.8) \mathrm{mg} / \mathrm{dl}$ in GDM and $(126.5 \pm 10.8) \mathrm{mg} / \mathrm{dl}$ in type $2 \mathrm{DM}$, which were significantly higher than the controls. In contrast, HDL cholesterol was significantly elevated in controls $(47.1 \pm 3.7) \mathrm{mg} / \mathrm{dl}$, compared to $\mathrm{GDM}(42.7 \pm 5.9) \mathrm{mg} / \mathrm{dland}$ type 2 DM women(39.6+2.5)mg/dl.

Table 3:Relationship between maternal age and lipid profile

\begin{tabular}{|c|c|c|c|c|c|}
\hline \multirow[t]{3}{*}{ Group } & \multicolumn{5}{|c|}{ Correlation of maternal age with } \\
\hline & TC & TGL & VLDL & LDL & HDL \\
\hline & P Value & P Value & P Value & P Value & P Value \\
\hline 1 & $0.02 *$ & 0.12 & 0.09 & 0.29 & 0.05 \\
\hline 2 & 0.90 & 0.78 & 0.76 & 0.61 & 0.38 \\
\hline 3 & 0.21 & 0.36 & 0.40 & 0.29 & 0.49 \\
\hline
\end{tabular}

\section{* - Significance}

No significant correlation was found between the maternal age and the lipid profile parameters except for the Total Cholesterol value which increased with maternal age in the control group alone.

\section{Discussion}

Women with GDM and type 2 DM are at high risk of maternal and fetal complications during pregnancy. Recent studies on experimental animals points towards an important role of intrauterine metabolic environment in the development of fetal malformation associated with diabetic pregnancy. Because diabetes produces changes in maternal metabolic fuels and because diabetic pregnancy is often associated with complications, the effects of maternal diabetes on lipid metabolism are unclear [15].The plasma lipid and lipoprotein changes in diabetic pregnancy have been studied by many researchers [16],[17].This study was designed to observe the changes in lipid profile in 
normal pregnancy (Group-1), GDM women (Group-2) and type $2 \mathrm{DM}$ women (Group-3).

Hyperlipidemia is a common feature in normal pregnancy and consists primarily of an increase in triglycerides with smaller rises in cholesterol [18]. Total cholesterol was studied in normal and GDM pregnancies by de Arcos [19] and results reported to show a trend towards being higher in GDM women.Recently, Schaefer-Graf et al.[20] found that maternal serum triglyceride levels significantly correlated with abnormal fetal growth in women with gestational diabetes mellitus. In our study results, there wasa significant elevation of total serum cholesterol in groups-2 and 3 when compared to group-1. LDLcholesterol and VLDL-cholesterol levels are also elevatedusually in pregnancy along with other lipids. A study done in 1982 by Hollingsworth [21]depicts changes in LDL-cholesterol where GDM patients failed to demonstrate a rise with pregnancy. Study results of deArcos[19]showed non-significant rise in LDL and VLDL-cholesterol in GDM patients when compared to normal pregnancy. Montelonge [18] reported significant increase in LDL-cholesterol in GDM groups in comparison to normal pregnancies. Our results are in agreement with the results of Montelonge [18] where significant difference was seen in LDL values among the groups. There is some evidence that not only TGL and Total cholesterol,but even the concentration of HDL-cholesterol is increased in pregnant women. Hollingsworth studied HDL-cholesterol levels in GDM women and values were found to be lower than in normal pregnancy. Our results showed significantly lower values in diabetic pregnancy compared to normal pregnancy,actual values being $(47.1 \pm 3.7),(42.7 \pm 5.9)$ and $(39.6 \pm 2.5) \mathrm{mg} / \mathrm{dlin}$ groups-1,2 and 3 respectively. From above results, it seems that diabetic subjects have lower HDL-cholesterol values which do not increase even under the influence of hyperlipidemia of pregnancy.

From our study it is evident that all the parameters of lipid profile except for HDL cholesterol is elevated in gestational diabetes and type $2 \mathrm{DM}$ in pregnancy than in controls. So, dietary modifications and appropriate treatment might reduce the fetal and maternal morbidity and mortality in a diabetic pregnancy.

\section{Conclusion}

In the present study, Total Cholesterol, Serum Triglycerides, VLDL and LDL levels were significantly elevated in GDM and pregnant type 2 DM women when compared to normal pregnant women. On the contrary, HDL cholesterol was found to be significantly elevated in controls. Therefore, our study shows that the lipid profile in a diabetic pregnancy alters in such a manner that could be harmful to the fetus. Extended studies are required to see the effect of these alterations on fetus. Early diagnosis and treatment of diabetic pregnancy will reduce the severity ofcomplications associated with this condition.

\section{Funding: Nil, Conflict of interest: Nil, Permission from IRB: Yes}

\section{References}

1. Ferris TF. Medical disorders during pregnancy, In: Harrison's principles of internal medicine, $14^{\text {th }} \mathrm{ed}, \mathrm{Mc}$ Crow Inc, 1998; pp 24-30.

2. Freinkel N. Banting Lecture 1980. Ofpregnancy and progeny. Diabetes. 1980 Dec;29(12):1023-35.

3. Silverman BL, Landsberg L, Metzger BE. Fetal hyperinsulinism in offspring of diabetic mothers. Association with the subsequent development of childhood obesity. Ann N Y Acad Sci. 1993 Oct 29;699:36-45.

4. Weiss PA, Scholz HS, Haas J, Tamussino KF, Seissler J, Borkenstein MH. Long-term follow-up of infants of mothers with type 1 diabetes: evidence for hereditary and nonhereditary transmission of diabetes and precursors.Diabetes Care. 2000 Jul;23(7):905-11.

5. Silverman BL, Metzger BE, Cho NH, Loeb CA. Impaired glucose tolerance in adolescent offspring of diabetic mothers. Relationship to fetal hyperinsulinism.Diabetes Care. 1995 May;18(5):61117.

6. Garber AJ. Vascular disease and lipids in diabetics.Med Clin North Am. 1998 Jul;82(4):931-48.

7. Gillmer, M. Diabetes in pregnancy, In: Oxford textbook of internal medicine. (1996). (3 ed., Vol. 02). Oxford University Press.

8. Kitajima M, Oka S, Yasuhi I, Fukuda M, Rii Y, Ishimaru T. Maternal serum triglyceride at 24--32 weeks' gestation and newborn weight in nondiabetic 
women with positive diabetic screens. Obstet Gynecol. 2001 May;97(5 Pt 1):776-80.

9. WasserstrumN. Maternal Physiology, In: Essentials of obstetrics and gynaecology, $2^{\text {nd }}$ ed, USA, WB Saunders Company, 1995;pp.61-73.

10. Gokcel A, Bagis T, Killicadag EB, Tarim E, Guvener N. Comparison of the criteria forgestational diabetes mellitus by NDDG and Carpenter and Coustan, and the outcomes of pregnancy. $\mathrm{J}$ Endocrinol Invest. 2002 Apr;25(4):357-61.

11. Allain CC, Poon LS, Chan CS, Richmond W, Fu PC. Enzymatic determination of total serum cholesterol. Clin Chem. 1974 Apr;20(4):470-75.

12. Bucolo G, David H. Quantitative determination of serum triglycerides by the use of enzymes. Clin Chem. 1973 May;19(5):476-82.

13. Burstein M, Scholnick HR, Morfin R. Rapid method for the isolation oflipoproteins from human serum by precipitation with polyamines.Journal of Lipid Research. 1970 Nov;11(6):583-95.

14. Friedewald WT, Levy RI, Fredrickson DS. Estimation of the concentration of low-density lipoprotein cholesterol in plasma, without use of the preparative ultracentrifuge. Clin Chem. 1972 Jun;18(6):499-503.

15. Knopp RH, Van Allen MI, McNeely M, Walden CE, Plovie B, Shiota K, Brown Z. Effect of insulindependent diabetes on plasma lipoproteins in diabetic pregnancy.J Reprod Med. 1993 Sep;38(9):703-10.
16. Schaefer-Graf UM, Pawliczak J, Passow

D, Hartmann $\quad$ R, Rossi R, Bührer $\quad$ C, Harder T, Plagemann A, Vetter K, Kordonouri O.Birth weight and parental BMI predict overweight in children from mothers with gestational diabetes.

Diabetes Care. 2005 Jul;28(7):1745-50.

17. Schaefer-Graf UM, Graf K, Kulbacka I, Kjos SL, Dudenhausen J, Vetter K, Herrera E. Maternal lipids as strong determinants of fetal environment and growth in pregnancies with gestational diabetes mellitus.Diabetes Care. 2008 Sep;31(9):1858-63.

18. Lasunción MA, Pallardo LF, Herrera E. Longitudinal study of plasma lipoproteins and hormones during pregnancy in normal and diabetic women. Diabetes. 1992 Dec;41(12):1651-59.

19. Sobki SH, Al-Senaidy AM, Al-Shammari TA, Inam SS, Al-Gwiser AA, Bukhari SA. Impact of gestational diabetes on lipid profiling and indices of oxidative stress in maternal and cord plasma. Saudi Med J. 2004 Jul;25(7):876-80.

20. Schaefer-Graf UM, Graf K, Kulbacka I, Kjos SL, Dudenhausen J, Vetter K, Herrera E. Maternal lipids as strong determinants of fetal environment and growth in pregnancies with gestational diabetes mellitus. Diabetes Care. 2008 Sep;31(9):1858-63.

21. Mazurkiewicz JC, Watts GF, Warburton FG, Slavin BM, Lowy C, Koukkou E. Serum lipids, lipoproteins and apolipoproteins in pregna nt non-diabetic patients. J Clin Pathol. 1994 Aug;47(8):728-31.

\section{How to cite this article?}

Vani K. Alterations in lipid profile in gestational diabetes mellitus (GDM) and type 2 DM women during pregnancy. Int J Med Res Rev 2015;3(8):800-804. doi: 10.17511/ijmrr.2015.i8.150. 